Fanum

Sociológico

\section{Forum Sociológico}

Série II

$29 \mid 2016$

Número 29

\title{
Infância, direitos e risco(s) : velhos e novos desafios identificados a partir da análise dos Relatórios da CNPCJR (2000 e 2010)
}

Childhood, rights and risk(s): old and new challenges identified from the analysis of the Reports of CNPCJR (2000 and 2010)

\section{Natália Fernandes e Catarina Tomás}

\section{OpenEdition}

Journals

Edição electrónica

URL: https://journals.openedition.org/sociologico/1470

DOI: 10.4000/sociologico. 1470

ISSN: 2182-7427

Editora

CICS.NOVA - Centro Interdisciplinar de Ciências Sociais da Universidade Nova de Lisboa

\section{Refêrencia eletrónica}

Natália Fernandes e Catarina Tomás, «Infância, direitos e risco(s) : velhos e novos desafios

identificados a partir da análise dos Relatórios da CNPCJR (2000 e 2010) », Forum Sociológico [Online], 29 | 2016, posto online no dia 31 dezembro 2016, consultado o 31 março 2022. URL: http:// journals.openedition.org/sociologico/1470 ; DOl: https://doi.org/10.4000/sociologico.1470 


\title{
INFÂNCIA, DIREITOS E RISCO(S): VELHOS E NOVOS DESAFIOS IDENTIFICADOS A PARTIR DA ANÁLISE DOS RELATÓRIOS DA CNPCJR (2000 E 2010) \\ CHILDHOOD, RIGHTS AND RISK(S): OLD AND NEW CHALLENGES IDENTIFIED FROM THE ANALYSIS OF THE REPORTS OF CNPCJR (2000 AND 2010)
}

\author{
Natália Fernandes \\ Universidade do Minho, Instituto de Educação \\ Catarina Tomás \\ Instituto Politécnico de Lisboa, Escola Superior de Educação \& Universidade Nova de Lisboa, Centro Interdisciplinar de \\ Ciências Sociais - Polo Universidade do Minho (CICS.NOVA.UMinho)
}

\begin{abstract}
Resumo
A análise da situação da infância em risco em Portugal caracteriza-se por um conjunto de avanços, impasses e retrocessos, na afirmação dos direitos da criança e na edificação de condições de bem-estar social para esta categoria social de tipo geracional. Através de um quadro teórico ancorado na Sociologia da Infância, este artigo tem como objetivo analisar os indicadores plasmados nos relatórios da Comissão Nacional de Proteção de Crianças e Jovens em Risco, em 2000 e em 2010. Propõe-se, assim, a partir de uma análise qualitativa e crítica, compreender as tensões e as ambiguidades que caracterizam a infância das crianças na sociedade portuguesa, em situação de risco, e os contornos que ele foi assumindo no período em análise.
\end{abstract}

Palavras-chave: direitos da criança, sociedade portuguesa, risco(s), políticas públicas para a infância

\begin{abstract}
The state of children at risk in Portugal has been characterized by a series of advances, setbacks and stalemates, in what concerns children's rights and the edification conditions of their welfare. From a sociological point of view, we analyzed the data embodied in the reports of the National Commission for the Protection of Children and Young People at Risk, in 2000 and 2010. Through a qualitative and critical analysis, we propose to understand the tensions and ambiguities that characterize children at risk and the shapes that this phenomenon has been assuming during this period in Portugal.
\end{abstract}

Keywords: children's rights, Portuguese society, risk (s), public policies for children

\section{Introdução}

A atualidade da problemática dos riscos, individuais e coletivos, tende a colocar-se de forma intensa nas sociedades contemporâneas, devido aos efeitos da globalização (Beck, 1992; Santos,
2001), da atual crise económico-financeira e as suas implicações nos direitos humanos, assumindo neste texto especial relevância os direitos da criança.

Um olhar atento sobre a realidade da infância e uma leitura particular sobre a infância em risco permite-nos constatar a situação paradoxal 
dos direitos da criança nas sociedades contemporâneas, com especial intensidade em sociedades semiperiféricas ou de desenvolvimento intermédio (Santos, 1994), como é o caso de Portugal, onde um quadro legislativo avançado não é acompanhado por práticas sociais e jurídicas concordantes com o mesmo.

Podemos afirmar que as crianças foram adquirindo ao longo do século passado um estatuto de sujeitos com direitos, pelo menos no campo dos princípios e dos discursos, que se consubstanciaram num corpus jurídico e teórico robusto e abundante, que influenciaram novos modos de pensar e intervir com esta categoria social.

No entanto, o século XXI iniciou-se com grandes turbulências e desassossegos, dos quais resultam impactos negativos no que diz respeito aos direitos das crianças, que parecem estar a desviar-se, cada vez mais, da sua concretização e, consequentemente, da sua não tradução na melhoria das condições de vida das crianças. Vivemos, assim, o início deste novo século, apreensivos com a crise económica e o aumento das desigualdades sociais, sendo as crianças um dos grupos sociais mais atingidos pelas mesmas (UNICEF, 2012a; 2012b).

Considerando este contexto, propomo-nos fazer uma análise comparativa dos dados dos relatórios da Comissão Nacional de Proteção de Crianças e Jovens em Risco (CNPCJR), com o objetivo de cartografar a situação das crianças em risco em Portugal, em retrospetiva, através da análise dos relatórios relativos ao ano de 2000 e de 2010.

Do ponto de vista metodológico, a construção deste artigo parte da análise dos dois relatórios, tentando assim compreender quais as faces do risco das crianças que chegam ao sistema de proteção. A exploração desta comparação potencia a exploração de inúmeras possibilidades de análise sobre a infância em risco em Portugal, ainda que neste artigo tenhamos presentes as limitações epistemológicas e metodológicas dessa mesma comparação, nomeadamente o fato de os dois relatórios se contextualizarem em dois modelos jurídicos diferenciados, isto é, o Relatório de 2000 no modelo da Organização Tutelar de Menores e o Relatório de 2010 na Lei de Proteção de Crianças e Jovens em Perigo. Mais ainda, a análise foi feita a partir de algumas opções que será necessário aqui dar conta: incidimos, somente, na análise dos processos instaurados pelas Comissões de Proteção de Crianças e Jovens (CPCJ) de forma a possibilitar a comparação e, assim, a configuração de cenários de risco; mantivemos não só as classificações/terminologias utilizadas em cada um dos relatórios, pois não era objetivo deste texto uma análise crítica dessas mesmas categorias, mas também os grupos etários que cada um dos relatórios apresentava. Significa que, em fim último, pautámos a análise dos dados e as comparações por alguma cautela em termos analíticos, ou seja, um registo mais descritivo e exploratório.

Esta análise terá como eixos orientadores a definição de um breve retrato sobre a infância, a família e o risco em Portugal nos anos em análise, com o objetivo de por um lado, caraterizar as faces novas e persistentes do risco e, por outro, interpelar estes dados e lançar algumas pistas para a compreensão dos (desas)sossegos da proteção das crianças em situação de risco.

\section{O conceito de risco e de proteção na sua relação com a infância}

Quando se discute a infância, o que nos diz a história é que o risco tem vindo a assumir diferentes matizes ao longo dos tempos. Loyd de Mause, um historiador da infância, defende que: "a história da infância é um pesadelo do qual só recentemente começamos a acordar. Quanto mais longe vamos na história, mais baixo e deficiente é o nível de cuidados para com a infância, maiores são as probabilidades de morte, abandono, espancamento e abuso sexual." (Mause, 1991: 1).

Reconhecemos, no entanto, que o século XX foi palco do surgimento de um intenso debate científico e de uma concetualização do risco na infância, que foi assumindo contornos cada vez mais amplos na sua própria definição e, de forma mais profunda, nas categorias que são usadas para o classificar.

O olhar clínico e patologizante sobre a problemática do risco na infância marcou o percurso de sistematização desta problemática, sendo posteriormente ampliado por outros olhares científicos, nomeadamente o da Psicologia, o qual ajudou a compreender as dimensões individuais, nomeadamente as características psicológicas dos vítimas e dos vitimizadores, como fatores explicativos das situações de risco (Machado, 1996; Sani, 2002); ou ainda, da Psicologia Social que alertou para a importância de ir além das meras características individuais dos sujeitos e mobilizar também os contextos onde ocorrem as interações entre as pessoas, como fatores importantes para a compreensão do risco (Garbarino e Sherman, 1980).

Nas discussões sociológicas é consensual a ideia de que vivemos em sociedades de risco (Areosa, 2008; Beck, 1992), fato que tem levado ao desenvolvimento de diferentes análises e múltiplos olhares, sendo difícil encontrar consensos na sua própria definição ${ }^{1}$. Como defende Areosa (2008), trata-se de uma questão bastante complexa, de difícil definição e objetivação, onde os seus limites e fronteiras são difíceis de delimitar "visto que a sua noção se converte em múltiplos significados e conotações sociais" (Areosa, 2008: 1). 
Segundo Hespanha (2002), o risco pode ser analisado a partir de duas perspetivas: por um lado, a ideia do risco associada ao dinamismo e à mudança social, sendo o risco um fator indispensável para que tal ocorra; por outro lado, a ideia que o risco implica incertezas nem sempre controláveis, sobretudo num contexto de economia mundializada.

Frade (2009) sugere também que, numa perspetiva sociológica do risco, é necessário identificar duas abordagens distintas: as que adotam uma conceção objetiva do risco e as que o consideram como uma construção social, "apesar de quase nenhum cientista defender hoje estes paradigmas no seu estado puro" (Frade, 2009: 55). A oposição dualista destas perspetivas não obriga a que as respostas sejam necessariamente exclusivas, tendo as duas perspetivas uma capacidade heurística. Ainda assim, a propósito da última perspetiva enunciada, a do risco enquanto construção social, Giddens (1991) defende que a sua análise dever ser socialmente situada em relação aos discursos e às estruturas socioeconómicas. Parece-nos que estas dimensões são importantes e especialmente úteis para ampliar a discussão no âmbito da temática da infância e do risco (Harden, 2000).

Talvez o único consenso que possamos descrever relativamente ao risco seja a ideia da multiplicidade de conceções sobre o mesmo, e a fluidez das suas diferentes características. Não obstante, são essas características que possibilitam o exercício político e científico de um olhar "dentro e fora do risco", ou seja, um olhar sobre os modos como as condições estruturais o provocam e alimentam, sendo estas complexas, dinâmicas e múltiplas, nomeadamente o espaço-tempo onde ocorre.

A este propósito consideramos que o risco na infância tem vindo a sofrer algum desgaste em termos conceituais e, consequentemente alguma trivialização. Um dos fatores responsáveis para que tal tenha acontecido relaciona-se com o impacto da sociedade de informação e comunicação. A este propósito, Carvalho e Ferreira (2009) defendem que a imprensa tem um papel fundamental na construção e divulgação de determinados tipos, nomeadamente "maus-tratos e abandono, violência sexual e crianças objecto de disputas familiares parecem ter-se tornado alvos de especial interesse" (Carvalho e Ferreira, 2009: 124). O espaço mediático reage, na maioria das vezes, à temática da infância quando associada a episódios alarmantes, construindo e distribuindo, para o efeito, determinadas imagens, demasiado simplistas e redutoras da realidade.

$\mathrm{Na}$ esteira desta reflexão propomos, em seguida, analisar o risco na infância, a partir dos relatórios já anunciados, considerando duas dimensões: o que se manteve inalterado e os novos traços desta problemática nos anos analisados.
Faces persistentes e renovadas da proteção e do risco na infância

É reconhecido que em Portugal, nas últimas duas décadas, têm merecido especial destaque os direitos de provisão e proteção das crianças o que nos levou a classificar este tempo como um período de "expansão da proteção" (Tomás, Fernandes e Sarmento, 2011). Para tal, contribuíram aspetos como a reforma do sistema jurídico de proteção das crianças, em 1999, que permitiu, entre outros aspetos, uma separação jurídica das crianças vítimas de negligência ou maus-tratos colocadas ao abrigo da Lei de Proteção de Crianças e Jovens em Perigo (Lei no 147/99, de 1 de setembro; Ministério do Trabalho e da Solidariedade) das crianças que cometeram delitos qualificados como crimes (Lei Tutelar Educativa - Lei no 169/99, de 14 de setembro; Ministério da Justiça) ${ }^{2}$ e institui a Comissão Nacional para a Proteção de Crianças e Jovens em Perigo (atualmente Comissão Nacional de Promoção dos Direitos e Proteção das Crianças e Jovens) .

É indiscutível que assistimos a uma ampliação do sistema de proteção de base sociocomunitária e de responsabilidade social coletiva, aspeto que é reconhecido por Pedroso e Branco (2008), quando referem que o Estado, em parceria com as autarquias e com as entidades associativas da comunidade, tem tido um papel muito importante na defesa e na ação em prol dos direitos da criança.

De registar, ainda, nesta tendência de expansão da proteção, a proibição dos castigos corporais a crianças, através da revisão do Código Penal, Lei 59/2007 de 4 de setembro, que expressamente consagra, pela primeira vez, no seu artigo 152, esta medida de proteção das crianças.

O percurso do último século, cujo início foi marcado pela quase ausência de documentos de proteção da infância e cujo remate se caracterizou pela existência de um significativo acervo de documentos legislativos a esse nível, leva-nos a afirmar que para além do idioma jurisdicista, assistimos a alguma vitalidade sociopolítica nesta área, uma vez que as preocupações com a proteção das crianças assumiram alguma visibilidade no desenvolvimento das políticas públicas para a infância, ainda que de baixa intensidade. Esta é justificada pelo fato de muitas crianças continuarem a ver a promoção dos seus direitos negada, muitas vezes de uma forma brutal, uma vez que os relatórios relativos à análise do fenómeno da pobreza e exclusão social (Bastos et al., 2008; OECD, 2009; OECD 2011; UNICEF, 2012b; Wall e Almeida, 2014) revelam que os indicadores de pobreza infantil e de exclusão continuam a afetar mais as crianças que os adultos, e que os indicadores de risco continuam a aumentar. Estes fatos devem interpelar-nos considerando que, provavelmente, tal como defende Gaitán (2006): "o desejo de alcançar 
o maior bem-estar das crianças é algo que se dá por feito, mas, no entanto, a definição do que se supõe ser o 'interesse superior da criança' fica ao arbítrio da interpretação adulta e está influenciado pelas convenções sociais que determinam o lugar e papel adequado para as crianças na sociedade" (Gaitán, 2006: 63).

Este é um fenómeno que, na nossa opinião, exige ser enfrentado para que as políticas públicas tenham efeitos mais consistentes e visíveis nos mundos das crianças, porque: as políticas públicas têm efeitos geracionais diferenciados. Não obstante, a avaliação dos impactos geracionais das políticas não é geralmente tida em conta. Similarmente, a intervenção dos vários grupos e categorias populacionais na construção do espaço público é atravessada por fatores de mobilização, por sistemas de crenças e representações sociais, e por dispositivos institucionais e políticos que diferenciam os direitos formais e as possibilidades reais de contribuição na decisão política (Sarmento, Fernandes e Tomás, 2007: 183).

A infância é especialmente afetada, entre todos os grupos e categorias sociais excluídas (grupos étnicos minoritários, pobres, mulheres, pessoas idosas, etc.), quer pela relativa invisibilidade face às políticas públicas e aos seus efeitos, quer por que é geralmente excluída do processo de participação e decisão na vida coletiva. Como defendem Davis e Hill (2006), são várias as dimensões a considerar quando se discutem as questões da exclusão social das crianças, uma vez que:

"estão enraizadas nas condições materiais das famílias e nas condições económicas da sociedade, mas outras estão relacionadas com as relações sociais, sejam intergeracionais ou intrageracionais. Uma forma de exclusão social corresponde aos modos como as crianças pobres são marginalizadas por falta de recursos materiais. Outra reporta-se aos modos pelos quais as crianças são excluídas das principais decisões, dentro ou fora dos contextos familiares, de tal modo que as suas preferências e desejos não são reconhecidos pelos adultos." (Davis e Hill, 2006: 14)
Inspiradas por este conjunto prévio de aspetos que nos auxiliam no olhar sobre a complexa realidade do risco na infância, apresentamos de seguida dados para mapear algumas das suas dimensões à escala nacional.

\section{As faces persistentes do risco}

O risco assumiu ao longo dos anos em análise um aumento no que diz respeito ao volume processual. Em 2000, o volume processual de processos instaurados foi de 3745 casos e em 2010 foi de 5444 casos, o que nos leva a afirmar que houve um significativo aumento de casos de crianças sinalizadas às CPCJ em todo o país (CNPCJR, 2001; 2011). Mas quem são as crianças que estão contidas na impessoalidade destes números?

Ao longo desta década o perfil destas crianças sofreu algumas modificações e noutras dimensões o perfil manteve-se. Relativamente ao que se manteve, podemos aqui apresentar uma caracterização sucinta dos dados.

A análise do quadro 1 remete-nos para o fato de que continuam a ser os meninos os que mais são sinalizados (ainda que seja pouca a diferença relativamente às meninas). As regiões de Lisboa e Vale do Tejo e Porto são as mais representativas no volume processual global nacional das CPC] (2011: 68), o que nos remete para a ideia da "metropolização do risco".

A negligência foi a principal problemática sinalizada (24,6\% em 2000; 38,2\%, em 2010). Os estabelecimentos de ensino (em 2000, 38\%; em $2010 ; 24,2 \%$ ) e as autoridades policiais foram as principais entidades sinalizadoras (em 2000, $8 \%$; em 2010, 19\%). O aspeto de novidade nesta dimensão prende-se com o fato de que em 2010 os pais/cuidadores passaram a ocupar o terceiro lugar, quando em 2000 eram os estabelecimentos de saúde.

No que diz respeito às medidas aplicadas, a opção de manter a criança ou jovem em meio natural de vida (em 2000, 70,1\%; em 2010, 90,6\%) foi a mais adotada. Em termos etários se não houve diferenças significativas no grupo de crianças até

Quadro 1 Perfil das crianças em risco em 2000 e 2010, em função do género, espaço e problemática

\begin{tabular}{|c|c|}
\hline Categorias & $\begin{array}{l}\text { Indicadores } \\
\text { Relatórios da CNPCJR ( } 2000 \text { e 2010) }\end{array}$ \\
\hline Género & Meninos mais sinalizados \\
\hline "Metropolização do risco" & $\begin{array}{l}\text { Lisboa e Vale do Tejo e Porto como as áreas mais representativas do volu- } \\
\text { me processual global nacional das CPCJ }\end{array}$ \\
\hline Principal problemática sinalizada & $\begin{array}{l}\text { Negligência } \\
\text { - 2000: } 24,6 \% \\
\text { - 2010: } 38,2 \%\end{array}$ \\
\hline
\end{tabular}

Fonte: CNPCJR (2001; 2011) 
Quadro 2 Perfil das crianças em risco em 2000 e 2010, em função das entidades sinalizadoras, medidas aplicadas e idade

\begin{tabular}{|c|c|}
\hline Categorias & $\begin{array}{l}\text { Indicadores } \\
\text { Relatórios da CNPCJR (2000 e 2010) }\end{array}$ \\
\hline Entidades sinalizadoras & $\begin{array}{l}\text { Estabelecimentos de ensino } \\
\text { - 2000: } 38 \% \\
\text { - 2010: } 24,2 \% \\
\text { Autoridades policiais } \\
\text { - 2000: } 8 \% \\
\text { - 2010: } 19 \%\end{array}$ \\
\hline Medidas aplicadas & $\begin{array}{l}\text { Manter a criança o jovem em meio natural de vida } \\
\text { - 2000: } 70,10 \% \\
\text { - 2010: } 90,6 \%\end{array}$ \\
\hline Idade & $10-14 / 15$ anos \\
\hline
\end{tabular}

Fonte: CNPCJR $(2001 ; 2011)$

aos 5 anos, uma vez que ele representava em 2000 cerca de $25 \%$ das crianças atendidas e $28,4 \%$, em 2010, as diferenças mais significativas situam-se com o grupo de jovens entre os 15/18 anos, uma vez que em 2000 representavam 3,77\%, aumentando em 2010 para 20,6\%. De referir, no entanto que há um indicador persistente nesta década: o fato de o maior número de crianças acompanhadas se situar no grupo etário entre os 10 e os 14/15 anos.

Outra dimensão crucial da imutabilidade dos dados foi o da caracterização das famílias das crianças com processo instaurado.

A análise sociológica dos principais indicadores permite-nos afirmar que a imagem de família que resulta da análise dos dois relatórios mantém exatamente o mesmo perfil: família biológica, nuclear, tendo os pais idades compreendidas entre os 35 e os 44 anos, com rendimentos provenientes do trabalho, com baixo capital escolar e tendo como principal problemática o alcoolismo. De referir, a este propósito, que algumas das medidas foram implementadas nos últimos anos no sentido de promover competências junto destas famílias, como o apoio junto de familiares, a educação e formação parental $^{3}$, a criminalização dos castigos físicos ${ }^{4}$, entre outras. Não obstante, o perfil manteve-se inalterado, o que nos remete para uma insuficiência de medidas de políticas de apoio à família, que interrompam e enfrentem esta realidade (Portugal, 2000; Wall, 2012).

As pesquisas de alcance nacional que caracterizam o fenómeno (Almeida et al., 1998; 1999; Amaro, 1986) e que se refletem na análise dos dados anteriores, são unânimes em afirmar que as situações de risco que envolvem crianças acontecem, principalmente, em contexto familiar. Esta é, no entanto, uma questão complexa, tanto mais que a maioria das crianças considera o espaço privado como um espaço de proteção e segurança. A este propósito, convocamos o contributo de Harden
(2000) quando identifica, a partir dos contributos das crianças, três esferas a partir das quais se pode considerar o risco. A autora defende que: as crianças constroem reflexivamente os seus cenários de risco e segurança à volta dos conceitos de privado, local e público. Enquanto a esfera privada da casa é descrita pelas crianças em termos de proteção e segurança, manifestam preocupações relacionadas com a sua vulnerabilidade na vida pública. Definem também uma esfera intermediária entre a pública e a privada - a esfera local - a qual é identificada em termos de proximidade da sua casa e de lugares e pessoas que para elas são familiares (Harden, 2000: 43).

Estamos, aparentemente, confrontados com uma questão de complexa resolução, que é aditada pela tendência de, modernamente, as crianças serem tematizadas a partir de uma "negatividade constituinte" (Sarmento, 2004), sem visibilidade social, com possibilidades cada vez mais limitadas de "espreitar" a esfera local a que se refere Harden (2000). O desenvolvimento de políticas com um enfoque muito paternalista e assistencialista exacerba esta invisibilidade das crianças noutras esferas que não a privada, deixando também no ar a dificuldade que há de enfrentar os riscos que ela corre no espaço privado, de ultrapassar a ideia de que esta é uma questão gerível, quase exclusivamente, no interior da família, o que nos remete para uma imagem das crianças enquanto objetos e não sujeitos de direitos.

Finalmente, da análise dos dois relatórios, uma outra dimensão deve ser realçada, a da localização das respostas sociais, ou seja, na sua grande maioria as situações de risco que envolvem as crianças, são sinalizadas e acompanhadas nos seus concelhos de naturalidade: tanto em 2000 como em 2010 a maioria das crianças eram naturais do concelho onde estava implementada a CPC] (73,9\% em 2000; $62 \%$ em 2010). 


\section{As novas faces do risco}

Nos anos em análise decorreram, no entanto, algumas alterações nas faces do risco para as crianças em Portugal. na sociedade portuguesa, nomeadamente com as questões da imigração (Machado, 2003) relaciona-se com o aumento das crianças sinalizadas e acompanhadas naturais de outros países: em 2000 representavam 2\% do total de crianças e em 2010

Quadro 3 Derfil das crianças em risco em 2000 e 2010, em função da idade das crianças, imigração, escolaridade e trabalho artístico

\begin{tabular}{l|l}
\hline Categorias & $\begin{array}{l}\text { Indicadores } \\
\text { Relatórios da CNPCJR (2000 e 2010) }\end{array}$ \\
\hline Crianças pequenas (0 aos 5 anos) & $\begin{array}{l}\text { Aumento dos processos } \\
\bullet 2000: 2 \%\end{array}$ \\
\hline Crianças imigrantes & $\bullet 2010: 17 \%$ \\
\hline Escolaridade - Crianças que não frequentam o ensino & $\bullet 2000: 18,6 \%$ \\
\hline Trabalho artístico & $\bullet 2010: 5,1 \%$
\end{tabular}

Fonte: CNPCJR $(2001 ; 2011)$

Relativamente ao que se alterou, um dado importante de referir, é o aumento dos processos relativos às crianças pequenas ( 0 aos 5 anos) no período em análise. Em 2000, as 519 crianças dos 0 aos 2 anos (273 meninos e 246 meninas) representavam cerca de metade do escalão etário dos 0 aos 5 anos e 13,9\% do total de crianças com processo instaurado. Em 2010, 7987 crianças dos 0 aos 2 anos (2125 meninos e 2058 meninas) representavam cerca de $55,3 \%$ do escalão etário dos 0 aos 5 anos e 15,3\% do total de crianças com processo instaurado. Na nossa opinião este aumento poderá estar relacionado, de alguma forma, com as alterações que aconteceram entre estas duas datas relativamente à frequência de estabelecimento de educação: se em 2000 apenas 5,6\% das crianças sinalizadas frequentavam o ensino pré-escolar, em 2010 esse número aumenta significativamente para $25,8 \%$, considerando ainda as cerca de $21,4 \%$ de crianças que frequentavam creche ou jardim de infância e que no relatório de 2000 não assumem qualquer expressão (CNPCJR, 2011: 87). A frequência de contextos formais de educação proporciona, entre outros aspectos, uma maior visibilidade e acompanhamento destas crianças, que de outro modo permaneceriam invisíveis ao sistema de proteção e sem possibilidade de poder ser desencadeada qualquer medida no sentido de as proteger.

Outra dimensão crucial da mudança da situação da sociedade portuguesa e que aqui se reflete tem a ver com a escolaridade, sendo possível encontrar uma diferença significativa entre a percentagem de crianças que não frequentavam o ensino em 2000 - 18,6\% -, tendo diminuído em 2010 para 5,1\%.

Outro dado significativo, que tem que ser entendido à luz das próprias mudanças verificadas já eram $17 \%$, sendo que o número de crianças oriundas dos países africanos de língua oficial portuguesa (PALOP) se manteve - (2\%). As crianças sinalizadas por trabalho infantil, fenómeno com grande expressão em Portugal até à década de 80 do século passado, assume hoje outros contornos. Houve uma mudança parcial sobre este fenómeno em Portugal, ainda que as condições estruturais se tivessem mantido (por exemplo, a competitividade sustentada em baixa remuneração, longas horas de trabalho, desigualdade salarial entre géneros, etc.). No relatório de 2000 foram identificados 9 casos de trabalho infantil (CNPCJR, 2000: 22), no relatório de 2010 esse número aumentou para os 26 casos (CNPCJR, 2011: 91), sendo também interessante verificar a alteração da própria designação para "exploração do trabalho infantil". A este propósito convocámos as palavras de Padilha (2010) no sentido de esclarecer algumas nuances entre estes dois conceitos: "considero fundamental uma relação entre o trabalho infantil e a exploração do trabalho infantil, pois a exploração circunscreve-se na perspectiva da alienação, máxima do capital, que resulta numa relação alheia do sujeito com o objecto (trabalho), coisificando, por conseguinte, transformando, aviltando, degradando os homens e o produtor do labor em mercadorias" (Padilha, 2010, s/p).

Ainda nesta dimensão, a novidade, entre o relatório de relativo ao ano de 2000 e o de 2010, prende-se com a consideração da participação de crianças menores de 16 anos em espetáculos ou outras atividades de natureza cultural, artística ou publicitária, sendo este um assunto ausente em 2000 e que assume uma visibilidade interessante no relatório de 2010. A este processo não está alheia a 
regulamentação, em 2004, do Código do Trabalho, aprovado pela Lei no 99/2003, de 27 de agosto, atribuída pela Lei no 35/2004, de 29 de julho, que incumbia as CPC] de autorizar ou não a participação de crianças com menos de 16 anos em espetáculos e outras atividades de natureza cultural, artística ou publicitária. Posteriormente em 2009, através da lei $105 / 2009$, de 14/9, houve algumas alterações ao disposto em 2004, que se relacionam, sobretudo, com a natureza das atividades proibidas e com a natureza da participação, estabelecendo-se uma distinção entre participação esporádica ou continuada. Os dados dizem-nos que, em 2010, foram iniciados 93 processos desta natureza, havendo 17 que transitavam do ano anterior. Foram solicitados 110 processos de autorização (93 iniciados em 2010; 17 processos transitados). Foram autorizados 65 processos e 33 foram indeferidos. De registar que ocorreu um aumento do número de comissões onde foram movimentados estes processos (CNPCJR, 2011: 131-134).

\section{Interpelando os (desas)sossegos da proteção das crianças em Portugal}

Como afirmámos inicialmente, a complexidade da sociedade portuguesa, enquanto sociedade de desenvolvimento intermédio ou semiperiférica reflete-se na análise que aqui apresentámos da situação das crianças em risco. Por conseguinte, não será exagero se afirmarmos que vivemos numa "sociedade dilemática" (Pais, 2007), nomeadamente entre a proclamação e a defesa, pelo menos ao nível dos discursos, dos direitos das crianças e severa restrição nas condições sociais do seu usufruto.

Se por um lado, assistimos, ao desenvolvimento de políticas sociais e de um conjunto de medidas para a infância e para as famílias ${ }^{5}$, que se refletiram na melhoria da situação das crianças e podem explicar alguns dos dados apresentados; por outro lado, no caso das crianças em situação de risco, parecem demorar a ter o impacto esperado. A persistência de problemáticas no interior das famílias, como o alcoolismo, que se manteve como o principal fator de adversidade das famílias maltratantes tem, necessariamente, que interpelar as políticas públicas de combate a este fenómeno. $\mathrm{O}$ mesmo se pode afirmar da principal face do risco das crianças: a negligência. Uma das grandes críticas apresentadas ao sistema de proteção de crianças em Portugal é a ausência de políticas preventivas eficazes, as quais deveriam permitir uma intervenção técnica qualificada junto das famílias e das crianças de forma a impedir que estas entrem em ciclos de risco, difíceis de quebrar e ultrapassar.

Consideramos que as dificuldades que estão subjacentes a este aspeto têm a ver com o fato de Portugal continuar a ser um país pautado por fortes desigualdades e exclusões sociais (Silva, 2009), sendo por esse motivo necessário recolocar as questões do risco na infância num quadro mais abrangente de discussão, nomeadamente o relativo às questões da pobreza e da exclusão social.

Face aos ciclos de reprodução geracional da pobreza, característicos da sociedade portuguesa, a questão que aqui se coloca é: apesar de ter havido um conjunto significativo de medidas implementadas no espaço que separa os dois relatórios em análise, porque não tiveram impacto na rutura deste ciclo? Será que, tal como referem Hespanha et al. (2000: 89-90), "a pobreza e a exclusão social reproduz-se ao longo das gerações, sem que exista capacidade de as superar"?

Assim, e de forma muito sucinta, defendemos que a exclusão social das crianças exige políticas para a infância de alta intensidade, articuladas e eficazes, e ainda que específicas, não podem ser dissociadas das políticas e medidas de âmbito mais geral do combate à exclusão. Mas será a aposta nesta especificidade que poderá ajudar a acautelar a ideia de que o bem-estar das crianças deverá ser ponderado a partir de três propostas: (i) mais e melhor conhecimento sobre as crianças e sobre as crianças em risco; (ii) mais e melhor acesso à justiça pelas crianças e suas famílias; (iii) mais políticas integradoras que assumam uma perspetiva geracional, tal como defende Gaitán (2006), quando refere que desta forma "contribui para por em relevo o lugar da infância como grupo social que compete com outros grupos sociais para aceder a recursos comuns, tendo como finalidade conseguir intercâmbios justos e mutuamente satisfatórios. Através dessa análise tornam-se explícitas as opções de preferência da sociedade relativamente a cada grupo social" (Gaitán, 2006: 75).

Talvez dessa forma, possamos combater a existência de "terceiro mundo interno" (Santos, 1993: 17), resgatando para a infância modos novos de combate à exclusão e marginalização dos seus direitos, consolidando, também, novas redes de proteção que permitam enfrentar a carga real e simbólica do risco de qualquer criança.

\section{Notas}

1 Para uma análise mais aprofundada do conceito de risco no campo sociológico, veja-se Areosa (2008) e Frade (2009).

2 Estas duas leis vêm substituir o modelo até então vigente consubstanciado na Organização Tutelar de Menores (DL n. ${ }^{\circ} 314 / 78$, de 27 de outubro). Para saber mais sobre o assunto, veja-se Santos (2004; 2010) e Carvalho (2013).

3 Cf. Lei 147/99, artigo $41^{\circ}$ - Educação Parental.

4 Art. ${ }^{\circ} 152$ do Código Penal, lei n. ${ }^{\circ} 59 / 2007$ de 4 de setembro. 
5 Algumas dessas medidas são: o rendimento social de inserção, a promoção da educação pré-escolar, a extensão das redes sociais locais, a aposta numa escolarização para todos e para todas, a constituição de equipas de intervenção precoce, o maior cuidado ao nível da saúde, o esforço de mobilização da opinião pública em redor das crianças e da sua proteção, promovida sobretudo por organizações da sociedade civil, pelos direitos das crianças (contra o trabalho infantil, contra a pedofilia, os maus tratos e mais recentemente pela promoção dos direitos de participação).

\section{Referências bibliográficas}

ALMEIDA, A. N.; I. André e H. Almeida (1999), "Sombras e marcas: os maus tratos às crianças na família", Análise Social, XXXIV (150), pp. 91-121.

ALMEIDA, A. N.; M. Guerreiro; C. Lobo; A. Torres e K. Wall (1998), "Relações familiares: mudança e diversidade", in J. M. Viegas e A. Costa (eds.), Portugal, que modernidade?, Lisboa, Celta, pp. 45-78.

AMARO, F. (1986), Crianças maltratadas, negligenciadas ou praticando mendicidade, Lisboa, CEJ.

AREOSA, J. (2008), "O risco no âmbito da teoria social", Actas do VI Congresso Português de Sociologia. Mundos sociais: saberes e práticas, pp. 1-16. Disponível em: http://www.aps.pt/vicongresso/ pdfs/323.pdf

BASTOS, A.; M. J. Malho; J. Passos e G. Fernandes (2008), Um olhar sobre a pobreza infantil. Análise das condições de vida das crianças, Coimbra, Almedina.

BECK, U. (1992), Risck Society. Towards a New Modernity, London, Sage Publications.

CARVALHO, M. J. (2013), Sistema nacional de acolhimento de crianças e jovens, Lisboa, Fundação Calouste Gulbenkian.

CARVALHO, M. J. e L. Ferreira (2009), "Infância e risco social: retratos da imprensa portuguesa", Sociologia, Problemas e Práticas, n. ${ }^{\circ}$ 60, pp. 105-129.

CNPCJR (s/d), Promoção e protecção dos direitos das crianças. Guia de orientações para os profissionais da acção social na abordagem de situações de maus-tratos ou outras situações de perigo, Lisboa, CNPCJR. Disponível em: http://www.cnpcjr.pt/ downloads/Guia_accao_social.pdf

CNPCJR (2001), Avaliação da actividade das comissões de protecção de crianças e jovens 2001, Lisboa, CNPCJR.

CNPCJR (2011), Relatório anual da actividade das comissões de protecção de crianças e jovens 2010, Lisboa, CNPCJR.

DAVIS, J. M. e M. Hill (2006), "Introduction", in E. Kay, H. Tisdall, M. Hohn Davis, H. Malcolm e A. Prout (eds.), Children, Young People and Social Inclusion: Participation for What?, UK, The Policy Press, pp. 1-22.

FRADE, C. (2009), "O direito face ao risco", Revista Crítica das Ciências Sociais, n. ${ }^{0}$ 86, pp. 53-72.
GAITÁN, L. (2006), "El bienestar social de la infancia y los derechos de los niños", Política y Sociedad, 43 (1), pp. 63-80.

GALLARDO, J. (1994), Maus-tratos à criança, Porto, Porto Editora.

GARBARINO, J. e D. Sherman (1980), "High-Risk Neighborhoods and High-Risk Families: The Human Ecology of Child Maltreatment", Child Development 51 (1), pp. 188-198.

GIDDENS, A. (1991), Modernity and Self-Identity: Self and Society in the Late Modern Age, Cambridge, Polity Press.

GILL, T. (2010), Sem medo. Crescer numa sociedade com aversão ao risco, Cascais, Princípia.

HARDEN, J. (2000), "There's no Place Like Home. The Public/Private Distinction in Children's Theorizing of Risk and Safety", Childhood, 7 (1), pp. 43-59.

HARDGROVE, A.; A. Enenajor e A.-J. Lee (2011), Risk and Childhood Poverty: Notes from Theory and Research, Oxford, University of Oxford/Young Lives.

HESPANHA, P. (2002), "Individualização, fragmentação e risco social nas sociedades globalizadas", Revista Crítica de Ciências Sociais, n.0 63, pp. 21-31.

HESPANHA, P.; A. Monteiro; A. C. Ferreira; F. Rodrigues; M. H. Nunes; M. J. Hespanha; H. Madeira; R. Van Den e S. Portugal (2000), Entre o Estado e o Mercado - As fragilidades das instituições de protecção social em Portugal, Coimbra, Editora Quarteto.

JAMES, A. (2008), "Changing Childhood in the UK: Reconstructing Discourses of 'Risk' and 'Protection'", in A. James e A. James (eds.), European Childhoods: Cultures, Politics and Childhoods in Europe, Basingstoke, Palgrave Macmillian, pp. 105-108.

JENKS, C. (1996), Childhood, London, Routledge.

MACHADO, C. (1996), "Maus tratos de menores, vitimização e poder: proposta de um modelo integrado de análise", Psicologia: Teoria, Investigação e Prática, n. 1, pp.133-148.

MACHADO, F. (2003), "Imigração e imigrantes em Portugal: parâmetros de regulação e cenários de exclusão", Sociologia Problemas e Práticas, n. 41, pp.183-188.

MADGE, N. e J. Barker (2007), Risk \& Childhood, London, RSA.

MAUSE, L.-D. (1991), Historia de la infancia, Madrid, Alianza Universidad.

OECD (2009), Doing Better for Children, Paris, OECD.

OECD (2011), Doing Better for Families, Paris, OECD.

PADILHA, M. (2010), "Trabalho, questão social e exploração do trabalho infantil no Brasil", Actas do III Encuentro Internacional contra el Trabajo Infantil. Disponível em http://encontrotrabalhoinfantil. fundacaotelefonica.com/users/miriamdamascenopadilha/work.

PAIS, J. M. (2007), "Cotidiano e reflexividade", Educação \& Sociedade, 28 (98), pp. 23-46. 
PEDROSO, João e Patrícia Branco (2008), "Mudam-se os tempos, muda-se a família. As mutações do acesso ao direito e à justiça de família e das crianças em Portugal", Revista Crítica de Ciências Sociais, n. ${ }^{\circ} 82$, pp. 53-83.

PORTUGAL, S. (2000), "Retórica e acção governativa na área das políticas de família desde 1974", Revista Crítica de Ciências Sociais, n. ${ }^{\circ}$ 56, pp. 81-92.

PROUT, A. (2005), The Future of Childhood: Towards the Interdisciplinary Study of Children, London, Routledge Falmer.

SANI, A. I. (2002), As crianças e a violência. Narrativas de crianças vítimas e testemunhas de crimes, Coimbra, Quarteto.

SANTOS, B. S. (1993), "O Estado, as relações salariais e o bem-estar social na semiperiferia: o caso português", in B. S. Santos (org.), Portugal: um retrato singular, Porto, Edições Afrontamento, pp. 17-56.

SANTOS, B. S. (1994), Pela mão de Alice. O social e o político na pós-modernidade, Porto, Afrontamento.

SANTOS, B. S. (2001), "Os processos da globalização", in B. S. Santos (org.), Globalização: fatalidade ou utopia?, Porto, Edições Afrontamento, pp. 31-106.

SARMENTO, M. (2004), "As culturas da infância nas

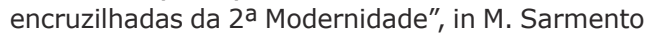
e A. Cerisara (orgs.), Crianças e miúdos. Perspectivas sócio-pedagógicas da infância e educação, Porto, Edições Asa, pp. 9-34.

SARMENTO, M.; N. Fernandes e C. Tomás (2007), "Participação infantil e políticas públicas", Educação, Sociedade e Culturas - Cidadanias, Género e Infância. Abordagens Pluridisciplinares, n. ${ }^{\circ}$ 25, pp.183-206.

SILVA, M. C. (2009), "Desigualdade e exclusão social: de breve revisitação a uma síntese proteórica", Configurações. Exclusões, Poderes e (sub)Culturas, 5/6, pp. 11-40.

TOMÁS, C.; N. Fernandes e M. Sarmento (2011), "Jogos de imagens e espelhos: um olhar sociológico sobre a infância e as crianças em Portugal", in V. Müller (ed.), Crianças dos países de Língua Portuguesa: histórias, culturas e direitos, Maringá, EDUEM, pp. 194-227.

UNICEF (2001), Situação mundial da infância 2011, Nova Iorque, UNICEF.

UNICEF (2012a), Situação mundial da infância 2012, Crianças em um mundo urbano, Nova Iorque, UNICEF.

UNICEF (2012b), "Measuring Child Poverty: New League Tables of Child Poverty in the World's Rich Countries", Innocenti Report Card 10, Florence, UNICEF Innocenti Research Centre.

VALENTINE, G. (1997), "Children Should be Seen and Not Heard: The Production and Transgression of Adults, 'Public Space'", Urban Geography, 17, pp. 205-220.

WALL, K. (org.) (2012), OFAP - Observatório das Famílias e das Políticas de Família. Relatório 2011, Lisboa, Instituto de Ciências Sociais da Universidade de Lisboa.

WALL, K. e A. N. Almeida (2014), As crianças e a crise em Portugal: vozes de crianças, políticas e indicadores sociais, Lisboa, UNICEF Portugal.

Recebido a 01/01/2014. Aceite para publicação a 28/06/2016.

Natália Fernandes (natfs@ie.uminho.pt). Universidade do Minho, Instituto de Educação. Campus de Gualtar, 4710-057 Braga, Portugal.

Catarina Tomás (ctomas@eselx.ipl.pt). Instituto Politécnico de Lisboa, Escola Superior de Educação \& Universidade Nova de Lisboa, Centro Interdisciplinar de Ciências Sociais - Polo Universidade do Minho (CICS.NOVA.UMinho). Campus de Benfica do IPL, 1549-003 Lisboa, Portugal. 